
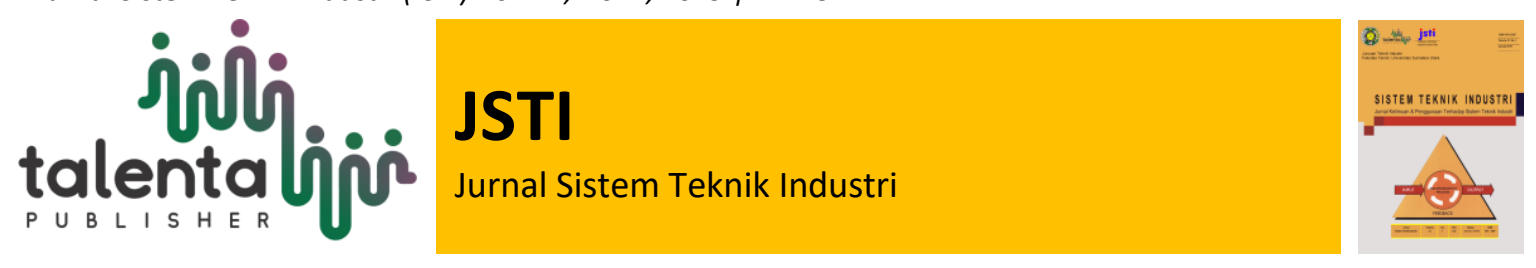

\title{
Analisis Kesehatan dan Keselamatan Kerja Berdasarkan Metode Fault Tree Analysis pada Area Packing Semen di PT. Lafarge Cement Lhokseumawe - Indonesia
}

\author{
Anwarl, Syukriah ${ }^{2}$, Ayu $^{3}$ \\ ${ }^{1}$ Dosen Teknik Industri ${ }^{2,3}$ Mahasiswa Teknik Industri, Universitas Malikussaleh
}

\begin{abstract}
Abstrak. PT. Lafarge Cement Indonesia Unit Area Packing yang berlokasi di Lhokseumawe Aceh adalah sebuah Perusahaan yang bergerak pada bagian pengantongan (packing) semen, yang mana semen itu sendiri diproduksi oleh PT.Lafarge Cement Indonesia yang berlokasi di Lhoknga Banda Aceh. Selama berjalannya kegiatan produksi terlepas dari terjadinya kecelakaan kerja sehingga penelitian ini bertujuan untuk mengetahui frekuensi kecelakaan dan jenis-jenis serta penyebab kecelakan di Perusahaan tersebut. Fault Tree Analysis (FTA) sebagai metode analisis data pada penelitian ini. Pada penelitian ini perhintungan angka kecelakaan kerja yang digunakan ialah frekuensi kecelakaan yang akan terjadi setiap 1.000.000 jam kerja, severity menyatakan hari kerja yang akan hilang setiap 1.000 .000 jam kerja, Safe-T-Score yang hasilnya menunjukkan perbandingan hasil tingkat frekuensi kecelakaan. Berdasarkan hasil penelitian, tingkat frekuensi pada tahun 2015 sebesar 316 dan severity 671, tahun 2016 sebesar 237 dan sebverity 474, tahun 2017 sebesar 197 dan severity 276, manakala tahun 2018 sebesar 39 kali yang akan terjadi kecelakaan setiap 1.000.000 jam kerja dan severity 79 yang akan hilang setiap 1.000 .000 jam kerja.. Hasil Safe-T-Score tahun 2016 ialah -707, 2017 ialah -414 dan tahun 2018 ialah -1792. Tingkat produktivitas kerja di $2015(0,9946)$, tahun $2016(0,9972)$, tahun $2017(0,9986)$ dan tahun $2018(0,9999)$. Kasus kecelakaan yang terjadi berupa sesak napas, iritasi pada mata, luka sobek, tersandung/terpleset, jari tangan terjepit dan tersetrum. pada tahun 2015 sebanyak 8 kasus, tahun 2016 sebanyak 6 kasus, tahun 2017 sebanyak 5 kasus dan tahun 2018 sebanyak 1 kasus. Fault Tree Analysis menghasilkan faktor penyebab dari kecelakaan kerja yang terjadi yaitu tindakan-tindakan dimana tidak memenuhi keselamatan kerja dan juga kondisi lingkungan kerja yang kurang nyaman.
\end{abstract}

Kata Kunci: 5s, Kaizen, Waste, 5R, Continues Improvement

*Corresponding author at: Jalan Raya Tlogomas 246 Malang

E-mail address: restuputri@umm.ac.id, dikawahyudin8@gmail.com 


\begin{abstract}
PT. Lafarge Cement Indonesia Area Packing Unit located in Lhokseumawe Aceh is a company engaged in cement packing, of which cement itself is produced by PT.Lafarge Cement Indonesia located in Lhoknga Banda Aceh. During the course of production activities regardless of the occurrence of workplace accidents so that this study aims to determine the frequency of accidents and the types and causes of accidents in the Company. Fault Tree Analysis (FTA) as a method of data analysis in this study. In this study, the number of occupational accident rates used is the frequency of accidents that will occur every 1,000,000 working hours, the severity of the working day will be lost every 1,000,000 working hours, the Safe-T-Score results show a comparison of the results of the frequency of accidents. Based on the results of the study, the frequency level in 2015 amounted to 316 and the severity of 671, in 2016 amounted to 237 and sebverity 474, in 2017 amounted to 197 and the severity of 276, when 2018 amounted to 39 times an accident occurred every 1,000,000 working hours and severity 79 which will be lost every 1,000,000 working hours ... Safe-T-Score results in 2016 are -707, 2017 is -414 and 2018 is -1792. Work productivity levels in 2015 (0.9946), 2016 (0.9972), 2017 (0.9986) and 2018 (0.9999). Accidents that occur in the form of shortness of breath, irritation of the eyes, wound torn, tripped / plugged, fingers pinched and electrocuted. in 2015 there were 8 cases, in 2016 as many as 6 cases, in 2017 as many as 5 cases and in 2018 as many as 1 case. Fault Tree Analysis produces the causal factors of work accidents that occur, namely actions which do not meet work safety and also the conditions of the work environment that are less comfortable.
\end{abstract}

Keyword: Fault Tree Analysis (FTA), Occupational Health and Safety, Productivity

Received 10 January 2019| Revised 26 January 2019 | Accepted 26 January 2019

\title{
1. Pendahuluan
}

Angka kecelakaan kerja di Indonesia menunjukkan angka yang sangat mengkawatirkan yaitu pada tahun 2014 angka kecelakaan kerja di Indonesia mencapai 14.519 kasus. Berdasarkan penelitian badan dunia International Labour Organization (ILO), Indonesia berada pada urutan ke 52 dari 53 negara dengan manajemen Kesehatan dan Keselamatan Kerja (K3) yang buruk. Padahal, biaya yang sangat besar akan dikeluarkan perusahaan akan bila terjadi kecelakaan ditempat kerja.

Seiring dengan berkembangnya teknologi yang digunakan, terjadi peningkatan potensi bahaya kecelakaan dan penyakit akibat kerja. Tentu hal ini menjadi prioritas setiap perusahaan untuk menjadikan program keselamatan dan kesehatan kerja sebagai acuan dasar seluruh perusahaan dalam menunjang keberhasilan suatu perusahaan. K3 adalah aspek penting dalam usaha meningkatakan kesejahteraan dan juga produktivitas karyawan.

Jika tingkat keselamatan kerja tinggi, kecelakaan yang menyebabkan sakit, cacat, dan kematian dapat ditekan seminimum mungkin. Begitu pula bila tingkat keselamatan kerja rendah, maka akan berpengaruh buruk terhadap kesehatan sehingga akan berkakibat pada produktivitas yang menurun.

PT. Lafarge Cement Indonesia unit area packing adalah sebuah Perusahaan yang berlokasi di Lhokseumawe bergerak pada bagian pengantongan semen, yang mana semen itu sendiri diproduksi oleh PT. Lafarge yang berlokasi di Lhoknga Banda Aceh. Dalam kegiatan produksi perusahaan tersebut tidak terlepas dari berbagai macam kecelakaan kerja yang disebabkan oleh beberapa faktor, seperti lingkungan kerja, mesin dan manusia. Hal ini perlu mendapat perhatian 
khusus karena akan berpengaruh kepada produktifias kerja dan produktifitas produksi pada perusahaan tersebut.

Dari uraian tersebut maka penulis melakukan Analisis Kesehatan dan Keselamatan Kerja dengan Metode Fault Tree Analysis Pada Area Packing Semen di PT. Lafarge Cement Indonesia Lhokseumawe"

Tujuan dari penelitian ini yaitu agar dapat mengetahui berapa tingkat frekuensi / kekerapan kecelakaan kerja dan tingkat severity yang terjadi serta mengidentifikasi penyebab dari kecelakaan dengan cara membangun model Fault Tree Analysis (FTA).

\section{Tinjauan Pustaka}

\subsection{Pengertan Kesehatan Kerja}

Kesehatan kerja adalah suatu hal yang penting sehingga perlu diperhatikan oleh perusahaan. Dengan adanya program kesehatan kerja yang baik, para karyawan akan diuntungkan secara material, karena akan menjadi lebih jarang absen yang disebabkan teman baik sekerja maupun tidak sekerja yang tertular. Lingkungan yang lebih menyenangkan dan nyaman untuk bekerja, sehingga karyawan secara keseluruhan akan mampu bekerja dengan lebih lama dan meningkatkan produktivitas lebih baik lagi.

Penilaian Keselamatan Kerja. Keselamatan kerja merupakan suatu upaya dalam melakukan pencegahan kecelakaan, cacat maupun kematian dikarenakan kecelakaan saat bekerja. Hal ini adalah faktor penting yang perlu diperhatikan selain kesehatan kerja, karena keselamatan kerja merupakan gerbang keselamatan bagi para karyawan. Tidak selamatnya karyawan dalam bekerja menjadi hambatan langsung bagi perusahaan, merugikan juga secara tidak langsung mulai dari rusaknya mesin dan peralatan kerja, terhentinya proses produksi dalam kurun waktu tertentu, kerusakan pada lingkungan, dan masih banyak lainnya.

\subsection{Metode Fault Tree Analysis}

Fault Tree Analysis adalah analisis dengan menggunakan pohon kesalahan yang secara sederhana dapat diuraikan sebagai suatu teknik untuk melakukan analisis. Pohon kesalahan merupakan suatu model grafis dimana pohon ini menyangkut penyebab-penyebab yang parallel dan memiliki kombinasi kesalahan-kesalahan yang dapat menyebabkan kejadian dari peristiwa yang tidak diinginkan, atau juga dapat diartikan sebagai gambaran umum timbal balik yang logis dari peristiwa-peristiwa dasar yang mempengaruhi ke arah peristiwa yang tidak diinginkan menjadi peristiwa puncak dari pohon kesalahan tersebut.

Langkah-langkah untuk membangun FTA adalah sebagai berikut :

1. Mendefinisikan kecelakaan. Kecelakaan yang sering terjadi di perusahaan pada dasarnya merupakan akibat dari para pekerja itu sendiri. Dikarenakan pekerja yang kurang berhati-hati saat melaksanakan pekerjaannya. 
2. Mempelajari system dengan mengetahui prosedur operasi, spesifikasi peralatan, serta lingkungan kerja.

3. Mengembangkan fault tree (Pohon kesalahan). Setelah kecelakaan didefinisikan, pohon kesalahan kemudian dikembangkan agar dapat ditemukan penyebab mendasar dari kecelakaan yang terjadi. Kemudian dicari solusi agar dapat mengantisipasi kecelakaan- kecelakaan yang terjadi

\section{Bahan dan Metode Penelitian}

Tahapan-tahapan dalam penelitian ini adalah yang pertama melakukan pengamatan lapangan, kemudian mengidentifikasikan masalan, dimulai dari mendefinisikan kecelakaan, mempelajari sistem, dan membangun pohon kesalahan, selanjutnya memastikan tujuan daripada penelitian tersebut erapan yaitu:

1. Agar dapat mengetahui tingkat frekuensi/kekerapan kecelakaan kerja dan tingkat severity yang ada.

2. Untuk mengidentifikasi Jenis-jenis kecelakaan dan penyebab mendasar kecelakaan dengan membangun model dari Fault Tree Analysis (FTA).

Setelah itu barulah dilakukan pengumpulan data, dimana data yang digunakan berupa data primer dan sekunder dalam penelitian ini. Data-data yang diperlukan antara lain: jumlah karyawan, jumlah jam kerja karyawan, jumlah kecelakaan karyawan, jumlah waktu kerja karyawan yang hilang, Setelah dilakukan pengumpulan data dilanjutkan dengan pengolahan data, model analisis yang digunakan adalah Fault Tree Analysis yang mana terbagi kepada kuantitatif dan kualitatif. Penelitian. Adapun formulasinya adalah:

1. Pengukuran Tingkat Frekuensi /kekerapan Kecelakaan (F)

Tingkat frekuensi merupakan jumlah kecelakaan yang terjadi setiap satu juta jam kerja manusia, ditunjukkan dengan rumus :

$$
F=\frac{n \times 1.000 .000}{N}
$$

Dengan:

$\mathrm{F}=$ Tingkat frekuensi kekerapan kecelakaan

$\mathrm{N}=$ Jumlah jam kerja karyawan

$\mathrm{n}=$ Jumlah kecelakaan yang terjadi

2. Pengukuran Tingkat Keparahan Kecelakaan Kerja atau Severity (S)

Tingkat severity merupakan banyaknya hari kerja yang hilang setiap satu juta jam kerja, dinyatakan dengan rumus

$$
S=\frac{H \times 1.000 .000}{N}
$$

Dengan:

$\mathrm{S}=$ Tingkat severity atau keparahan kecelakaan 
$\mathrm{N}=$ Jumlah jam kerja karyawan

$\mathrm{H}=$ Jumlah hari kerja yang hilang.

3. Pengukuran Nilai Safe-T-Score

Hasil tingkat kecelakaan suatu unit kerja pada masa lampau dibandingkan dengan masa kini agar dapat diketahui berapa tingkat penurunan kecelakaan yang terjadi, dinyatakan dengan rumus :

Dengan:

$$
\text { Safe }-T-\text { Score }(S T S)=\frac{F 2-F 1}{\sqrt{\frac{F 1}{N}}}
$$

STS $=$ Nilai T selamat tanpa dimensi

$\mathrm{N}=$ Jumlah jam kerja karyawan

F1 = Tingkat frekuensi kecelakaan kerja masa lampau

F2 = Tingkat frekuensi kecelakaan kerja masa sekarang

\section{Analisis Data dan Pembahasan}

Hasil dari Tingkat Frekuensi Rate/Kekerapan Kecelakaan (F) yang diukur:

Table 1 Frekuensi Kecelakaan (F)

\begin{tabular}{lll}
\hline Tahun & $\begin{array}{l}\text { Jumlah Kasus } \\
\text { Kecelaakan } \\
\text { Kerja }\end{array}$ & $\begin{array}{l}\text { Frekuensi } \\
\text { kecelakaan } \\
\text { (kali) }\end{array}$ \\
\hline 2015 & 8 kasus & 316 \\
2016 & 6 kasus & 237 \\
2017 & 5 kasus & 197 \\
2018 & 1 kasus & 39 \\
\hline
\end{tabular}

Pada tabel 1: dapat dilihat bahwa tahun 2015 tingkat frekuensi kecelakaan kerja sebanyak 316 kali yang akan terjadi persejuta jam kerja dengan 8 jenis kasus. Pada tahun 2016 dengan 237 kecelakaan terjadi dan kecelakaan persejuta jam kerja diperkirakan sejumlah 6 kasus, tahun 2017 frekuensi kecelakaan yang terjadi 197 kecelakaan persejuta jam kerja dengan 5 kasus dan tahun 2018 frekuensi kecelakaan 39 persejuta jam kerja dengan 1 kasus. Ini menyatakan bahwa frekuensi kecelakaan tertinggi yang terjadi pada tahun 2015 dan terendah pada tahun 2018, artinya bahwa pihak perusahaan berupaya terus agar frekuensi kecelakaan setiap tahun semakin berkutang agar produktvitas kerja karyawan dan produktivitas produksi semakin meningkat.

Pengukuran Tingkat Severity atau Keparahan Kecelakaan Kerja (S). Adapun hasil pengukuran tingkat keparahan kecelakaan kerja atau severity tahun 2015, 2016, 2017 dan 2018 ditunjukkan pada Tabel 2 berikut: 
Table 2 Frekuensi Kecelakaan (F)

\begin{tabular}{lll}
\hline & $\begin{array}{c}\text { Jumlah Hari } \\
\text { Kerja } \\
\text { Hahun }\end{array}$ & S (Hari) \\
\hline 2015 & 17 & 671 \\
2016 & 12 & 474 \\
2017 & 7 & 276 \\
2018 & 2 & 79 \\
\hline
\end{tabular}

Pada tabel 2: terlihat bahwa pada tahun 2015 jumlah hari kerja hilang sebanyak 17 hari, dengan tingkat severity sebanyak 671 hari yang akan hilang persejuta jam kerja. Begitu pula pada tahun 2016 sebanyak 12 hari yang hilang dan diperkirakan tingkat severity 474, sementara pada tahun 2017 banyak hari yang hilang sebanyak 7 hari dengan tingkat severity 276 hari hilang persejuta jam kerja dan di tahun 2018 banyak hari yang hilang sebanyak 2 hari dengan tingat severity 79 hari hilang persejuta jam kerja.

Hasil dari pengukuran Nilai T selamat pada 2015, 2016, 2017 dan 2018 ditunjukkan pada Tabel 3 berikut:

Table 3 Data Pengukuran Nilai Tselamat 2015-2018

\begin{tabular}{cccccc}
\hline Tahun & $\begin{array}{c}\text { Jumlah } \\
\text { Kecelakaan } \\
\text { Kerja }\end{array}$ & $\begin{array}{c}\text { Jumlah Jam } \\
\text { Pekerja }\end{array}$ & F1 & F2 \\
\hline 2015 & 8 & & 25.334 & - & 31 \\
2016 & 6 & 25.334 & 31 & 23 \\
2017 & 5 & 25.334 & 23 & 19 \\
2018 & 1 & 25.334 & 19 & 39 \\
\hline
\end{tabular}

Berdasarkan dari data-data kecelakaan kerja yang diperoleh dari bagian produksi PT. Lafarge Cement Indonesia maka dapat dianalisis akar permasalahan dari setiap kecelakaan kerja yang terjadi dengan pendekatan Fault Tree Analysis, jumlah setiap kasus kecelakaan kerja ditunjukkan pada tabel 4. 
Table 4 Jenis dan Jumlah Gangguan Kerja

\begin{tabular}{lll}
\hline No. & Gangguan Kerja & Jumlah \\
\hline 1. & Pernapasan & 7 \\
2. & Iritasi Mata & 5 \\
3. & Tersandung/Terples & 4 \\
& et & \\
4. & Jari Tangan Terjepit & 1 \\
5. & Tersetrum & 2 \\
6 & Luka Sobek & 1 \\
\hline Total & & $\mathbf{2 0}$ \\
\hline
\end{tabular}

\section{Kesimpulan}

Berdasarkan pengukuran dan perhitungan tingkat frekuensi/kekerapan kecelakaan kerja $(\mathrm{F})$ tahun 2015 yaitu 316 dan pada tahun 2016 ialah 237. Kemudian pada tahun 2017 tingkat frekuensi kecelakaan kerja ialah 197 manakala pada tahun 2018 yaitu 39 kali terjadi tiap satu juta jam kerja. Sementara untuk hasil pengukuran dan perhitungan pada tingkat keparahan kecelakaan kerja atau severity (S) pada 2015 yaitu 671 dan pada tahun 2016 ialah 474, pada tahun 2017 ialah 276 sementara pada tahun 2018 ialah 79 hari.

Jumlah jenis kasus kelakaan yang terjadi pada tahun 2015 sebayak 8 kasus, tahun 2016 sebanyak 6 kasus, tahun 2017 sebanyak 5 kasus manakala tahun 2018 sebanyak 1 kasus.

Berdasarkan model Fault Tree Analysis (FTA) yang telah dibangun penyebab masalah kecelakaan yang terjadi di PT. Lafarge Cement Indonesia terdiri dari dua aspek yaitu berdasarkan tindakan- tindakan yang tidak memenuhi tindakan keselematan (Unsafe Human Action) dan berdasarkan keadaan lingkungan yang tidak aman (Unsafe Conditions) dengan jenis kecelakaannya yaitu: sesak napas, iritasi pada mata, luka sobek, tersandung dan terpleset, jari tangan terjepit dan tersetrum.

\section{REFERENSI}

[1] Budiono. 1992. Bunga Rampai Hiperkes dan Keselamatan Kerja.Jakarta. PT. Tri Tunggal Tata Fajar

[2] Dainur. 1995. Materi - materi Ilmu Kesehatan Masyarakat. Widya Medika, Jakarta.

[3] Dessler, Gary. 1997. Manajemen Sumber Daya Manusia. Terjemahan oleh Benyamin Molan. Edisi Bahasa Indonesia.

[4] Filippo, Edwin, B. 1994. Manajemen Personalia. Terjemahan oleh Moh. Masud. Edisi keenam. Erlangga, Jakarta.

[5] Foster, ST. (2004). "Managing Quality: an Integrative Approach".

[6] Pearson Education International

[7] Hirzy Pradipta, dkk, 2015. Analisa Kesehatan dan Keselamatan Kerja Proyek Menggunakan Fault Tree Analysis (FTA) (http://sipil.studentjournal.ub.ac.id/ind ex.php/jmts/article/view/268, diakses tanggal 17 September 2018)

[8] International Labour Office, 1982.Pencegahan Kecelakaan Kerja.Jakarta. Senopress Offset

[9] International Labour Office, 1989. Pencegahan Kecelakaan Kerja. Jakarta PT. Pustaka Binanam Presindo PT Prennhallind, Jakarta., 
[10] Mustika, dkk. 2014. Analisa Keterlambatan Proyek Menggunakan Fault Tree Analysis (FTA). (http://sipil.studentjournal.ub.ac.id/ind ex.php/jmts/article/view/116, diakses tanggal 17 September 2018)

[11] Philipus Adyatama Igo, 2014. "Fault Tree Analysis (FTA) Pada Bagian Electric Arc

[12] Suma'mur.1981. Keselamatan kerja dan pencegahan kecelakaan. Gunung Agung, Jakarta.

[13] Suma'mur .1985. Keselamatan kerja dan pencegahan kecelakaan. Gunung Agung, Jakarta.

[14] Suma'mur, P.K, 1987, Keselamatan Kerja dan Pencegahan Kecelakaan Kerja. CV Haji Masagung, Jakarta.

[15] Suma'mur P.K. 1996. Higiene Perusahaan dan Kesehatan Kerja. PT. Gunung Agung, Jakarta.

[16] Tarwaka, 2008, Manajemen dan Implementasi K3 di Tempat Kerja,Surakarta, Harapan Press

[17] Tarwaka, 2016. Dasar-dasar Keselamatan Kerja serta Pencegahan di Tempat Kerja, Surakarta, Harapan Press.

[18] Ukhisia, Bella Gloria dkk. 2013. Analisis Pengaruh Keselamatan dan Kesehatan Kerja Terhadap Poduktivitas Karyawan. Universitas Brawijaya. Widuri, A. 1992. Psikologi Industri. HIPSMI 